\title{
Transformation of the microstructure and properties of ultrafine- grained TiNi alloys during the processing by ECAP-conform via the isothermal regime
}

\author{
Anna Churakova ${ }^{1,2,3^{*}}$, Dmitry Gunderov ${ }^{1,2,3}$, and Georgy Raab ${ }^{1}$ \\ ${ }^{1}$ Ufa State Aviation Technical University, 12 K. Marx str, Ufa 450008 Russia \\ ${ }^{2}$ Institute of Molecule and Crystal Physics, Ufa Research Center RAS, 151 pr. Oktyabrya, Ufa 450075 Russia \\ ${ }^{3}$ Saint Petersburg State University, 7/9 Universitetskaya nab., St. Petersburg, 199034 Russia
}

\begin{abstract}
This paper examines a technique for producing a TiNi alloy with an ultrafine-grained structure and enhanced mechanical characteristics. It is demonstrated that the use of the ECAP-Conform technique enables producing TiNi alloy samples with an ultimate tensile strength of up to $1300 \mathrm{MPa}$ and a rather high level of ductility. Studies show that in this alloy, there forms a banded deformation microstructure with a structural element size of up to $300 \mathrm{~nm}$, and during subsequent annealings there forms a grain structure with a grain size of about $200 \mathrm{~nm}$.
\end{abstract}

\section{Introduction}

Alloys based on titanium nickelide are well-known functional materials with the shape-memory effect (SME), conditioned by thermoelastic martensitic transformations. These alloys stand out among materials having functional characteristics, enhanced strength and ductility, and a good set of performance properties: a long life, corrosion resistance, biocompatibility, etc. [12]. For many cases of application, especially in critical or small-sized items, the level of mechanical and functional properties that TiNi alloys possess in their normal coarse-grained state is insufficient. Since physico-mechanical properties are structurally sensitive ones, methods of deformation-and-thermal treatment are traditionally used for their enhancement.

New possibilities in the control of the physicomechanical properties of metals and alloys are opened by the formation of an ultrafine-grained (UFG) structure by severe plastic deformation (SPD) processing [3,4]. A promising direction in the enhancement of service properties of TiNi alloys is the formation of a nanostructured state in them through SPD processing [512]. At present, well-developed in physical materials science is the fabrication of bulk amorphous and nanocrystalline materials using such SPD techniques as high-pressure torsion (HPT) and equal-channel angular pressing (ECAP) [3,5]. Both of these techniques are based on shear deformation and enable effecting large strains without fracture of the billets $[3,5]$. However, the HPT technique enables producing only small-sized samples for research purposes. For the manufacture of many items, in particular, dental implants, nanostructured TiNi is required, in the form of rodshaped semi-products with a diameter of 4-5 $\mathrm{mm}$.
Fabrication of large-sized TiNi alloy billets with a refined structure and enhanced properties is possible through the use of ECAP processing.

Nevertheless, the conventional ECAP technique has significant disadvantages that limit its use in industry: a relatively small productivity, the ability to produce only relatively short cylindrical samples, as well as the need to remove the edge parts of billets that have undergone repeated working during the deformation processing, which reduces the metal utilization factor. Free from these disadvantages is the technique of equal-channel angular pressing combined with Conform (ECAP-C) [13-16]. ECAP-C solves the above-mentioned problems, typical of conventional ECAP: it enables producing by deformation immediately a long-length rod (semiproduct); this technique has a high metal utilization factor and a high productivity [16]. The first experiments on the ECAP-C processing of TiNi alloys were already conducted earlier [17]. However, the ECAP-C facility available at that time made it possible to perform isothermal pressing at temperatures not higher than $200^{\circ} \mathrm{C}$. As a result of 2-4 cycles of ECAP-C processing at $200^{\circ} \mathrm{C}$ with intermediate annealings, a subgrain nanostructure was produced in the samples [17]. Still, when the number of cycles was increased to more than 4 , the TiNi samples fractured [17]. As of today, our research team has created an ECAP-C facility with a working temperature of up to $500^{\circ} \mathrm{C}$. The present work studies the effect of ECAP-C processing at an elevated temperature on TiNi, using this new facility, with a view to increase the number of processing cycles, produce in TiNi a UFG state with refined grains and enhanced mechanical characteristics.

* Corresponding author: churakovaa_a@mail.ru 


\section{Materials and research methods}

\subsection{Material under study}

As the object of study, the $\mathrm{Ti}_{49.1} \mathrm{Ni}_{50.9}$ alloy with a large $\mathrm{Ni}$ content with respect to the stoichiometry with the temperature $\mathrm{A}_{\mathrm{f}}=10^{\circ} \mathrm{C}$ was selected. At room temperature, the major phases in this alloy are austenite with a B2 crystalline lattice and the $\mathrm{Ti}_{2} \mathrm{Ni}_{3}$ phase, enriched with Ni. In order to form a solid solution based on TiNi, quenching of the alloy was conducted from the homogeneity region (from $800^{\circ} \mathrm{C}$ ) in water. During the subsequent heating of the quenched alloy $\mathrm{Ti}_{49.1} \mathrm{Ni}_{50.9}$, decomposition of the solid solution took place, with a successive precipitation of the excess phases $\mathrm{Ti}_{3} \mathrm{Ni}_{4}$, $\mathrm{Ti}_{2} \mathrm{Ni}_{3}, \mathrm{TiNi}_{3}$.

\subsection{Research methods}

The schematic diagram of the ECAP-C facility is presented in Fig. 1.

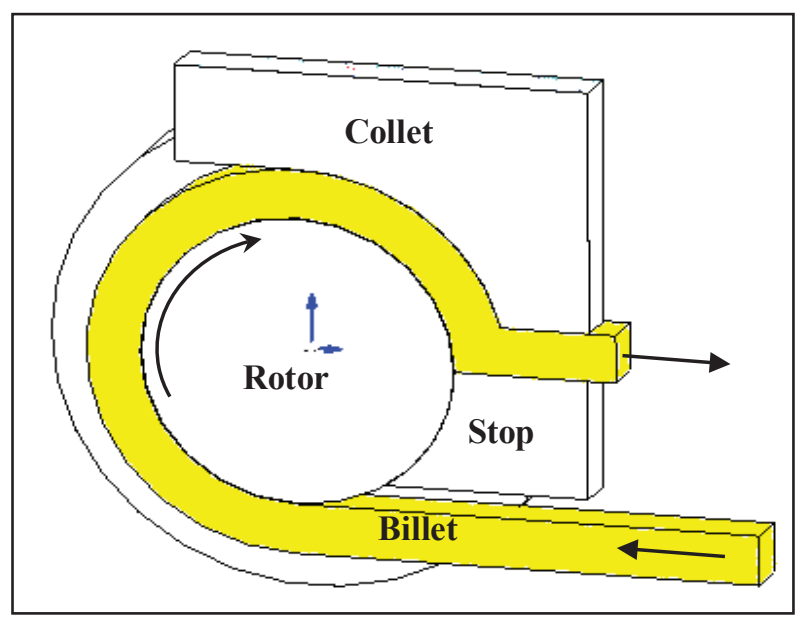

Fig. 1. Schematic diagram of the experimental facility for ECAP-Conform processing.

The facility created at Ufa State Aviation Technical University enables processing long-length rods of various metals with a diameter of up to $12 \mathrm{~mm}$, both at room temperature and at elevated temperatures. In the present study, a variant of this facility was used that enabled the pressing of rods with an initial diameter of $10 \mathrm{~mm}$. The following regime of ECAP-C processing was applied: two cycles at a temperature of $500^{\circ} \mathrm{C}$ (the condition «ECAP-C $n=2 »)$, then the same billet was subjected to two cycles of ECAP-C processing at a temperature of $400^{\circ} \mathrm{C}$ (the condition $《 \mathrm{ECAP}-\mathrm{C} \mathrm{n}=4$ »), and finally two cycles at a temperature of $450^{\circ} \mathrm{C}$ (the condition «ECAP-C $n=6 »)$, the angle of channels intersection was $130^{\circ}$. The temperatures were varied, starting with $500^{\circ} \mathrm{C}$, in order to evaluate the possibilities of ECAP-C processing of a $\mathrm{Ti}_{49.1} \mathrm{Ni}_{50.9}$ alloy billet without fracture. Then the temperature was decreased to $400^{\circ} \mathrm{C}$ (a temperature comparable to the temperature of conventional ECAP processing) and increased to $450^{\circ} \mathrm{C}$, on the basis of evaluation of the billet's integrity. After every two cycles, a sample was cut off from the billet for further investigation.

Microstructural study was performed using an OLYMPUS GX5 optical microscope. Microhardness was tested using a Micromet-5101 microhardness tester under a load of $1 \mathrm{~N}$. Tensile mechanical testing was performed on a tensile testing machine, designed at the Institute of Physics of Advanced Materials, Ufa State Technical University, with an upper load limit of $200 \mathrm{~kg}$ and a measurement accuracy of $5 \%$. The tests were conducted at room temperature, at a strain rate of $10^{-3} \mathrm{~s}^{-1}$, using flat micro-samples with a gauge section of $0.25 \times 1.0 \mathrm{~mm}$ and a gauge length of $3 \mathrm{~mm}$. Structural studies by transmission electron microscopy (TEM) were performed using a JEOL - 2100 transmission microscope with an accelerating voltage of $200 \mathrm{kV}$.

\section{Results and discussion}

\subsection{Microstructural studies by metallography and transmission electron microscopy}

According to optical metallography (OM), in the initial state the $\mathrm{Ti}_{49.1} \mathrm{Ni}_{50.9}$ alloy had an austenitic structure with a grain size of about 50-60 $\mu \mathrm{m}$ (Fig. 2, a). In the samples processed by ECAP-C (Fig. 2, c), with the help of OM one can see old boundaries of individual grains, and at the same time, regions in the boundaries of the initial grains have a strongly refined structure. Observation by $\mathrm{OM}$ of old grain boundaries and regions with different degrees of deformity can be accounted for by the fact that the crystallographic orientations of neighboring grains are directed at different angles with respect to the deformation axis, so the internal structure of grains undergoes deformation in a different manner. However, this issue requires further study.

The resolution of the OM method is not sufficient for showing the microstructure of samples after ECAP-C at the micro-scale.

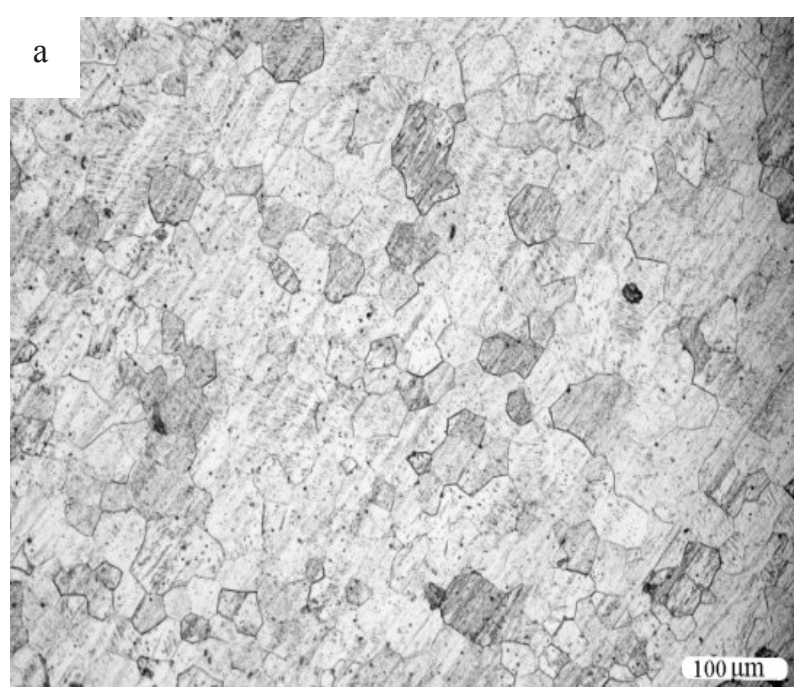



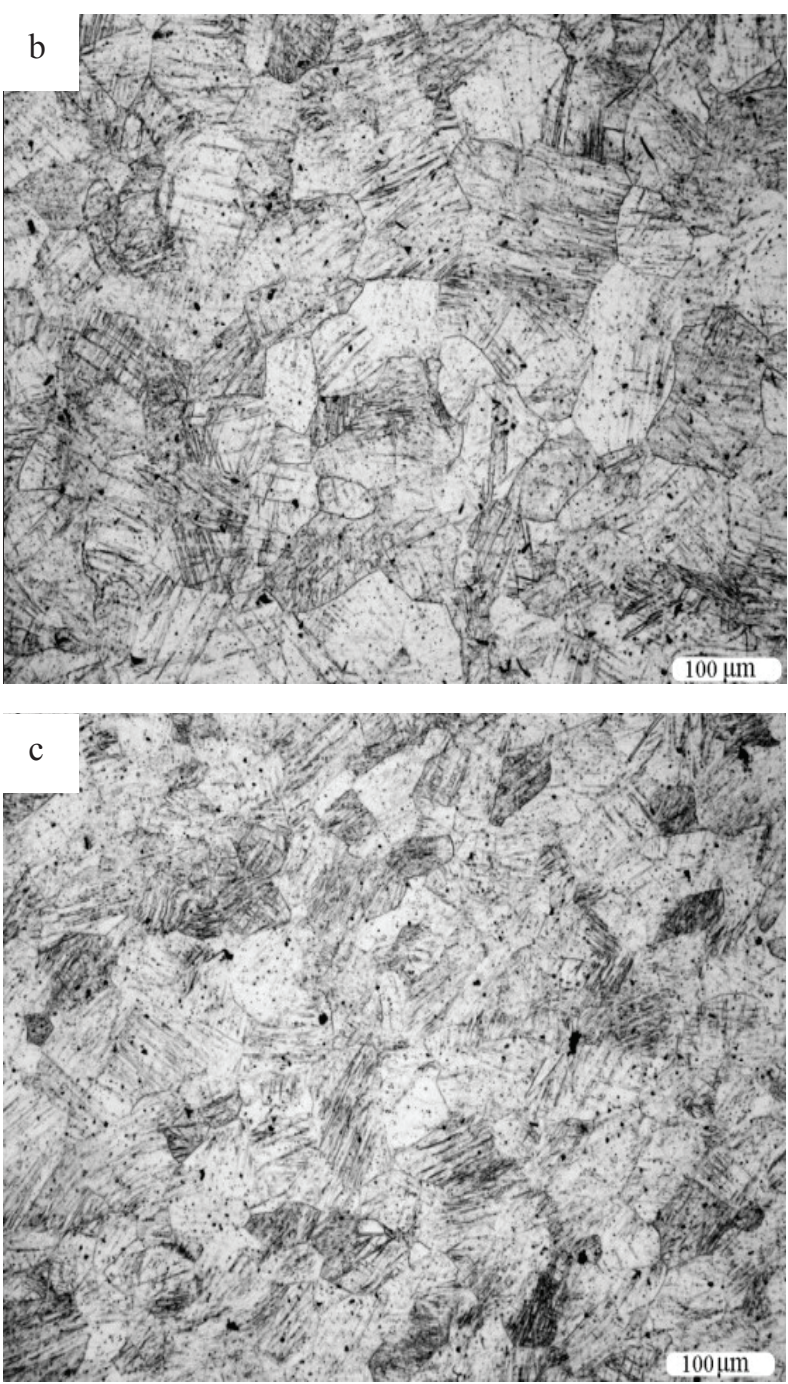

Fig. 2. Microstructure of the $\mathrm{Ti}_{49.1} \mathrm{Ni}_{50.9}$ alloy: a) initial state; b) ECAP-C, $n=4, T=400^{\circ} \mathrm{C}$; c) ECAP-C, $n=6, T=450^{\circ} \mathrm{C}$.

TEM studies demonstrate that in the $\mathrm{Ti}_{49.1} \mathrm{Ni}_{50.9}$ alloy subjected to ECAP-C there forms a banded microstructure with a high dislocation density and a developed fragmented structure inside the bands. The sizes of the deformation bands and fragments are presented in table 1. In the cross section of the rod after processing by ECAP-C with the number of passes $n=2$, regions are observed, having a banded deformation structure (Fig. 3) with a band width of about $500 \mathrm{~nm}$ and a length of several microns. Inside the bands, a high dislocation density is revealed. The electron diffraction pattern, showing a strong azimuthal and radial blurring of reflections, also confirms the formation in the alloy of a refined structure with a developed dislocation substructure and a high level of internal stresses due to work hardening.
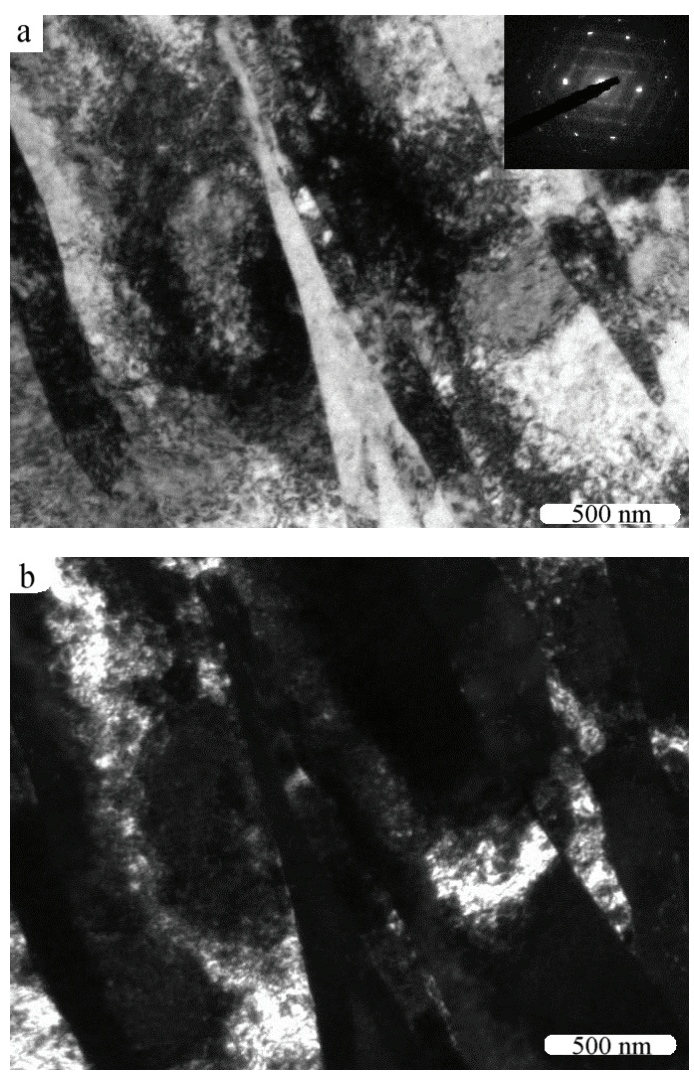

Fig. 3. Microstructure of the $\mathrm{Ti}_{49 .} \mathrm{Ni}_{50.9}$ alloy subjected to ECAP-C $\left(n=2, T=500^{\circ} \mathrm{C}\right)$ : bright-field image (a); dark-field image (b).

As the strain increases to 4 passes of ECAP-C, the structure becomes even more fragmented (Fig. 4). In the longitudinal section there form subgrains having rough dislocation walls, the dislocation density in the interior of grains/subgrains grows, which leads to an increase in internal stresses and, consequently, to progressing fragmentation.

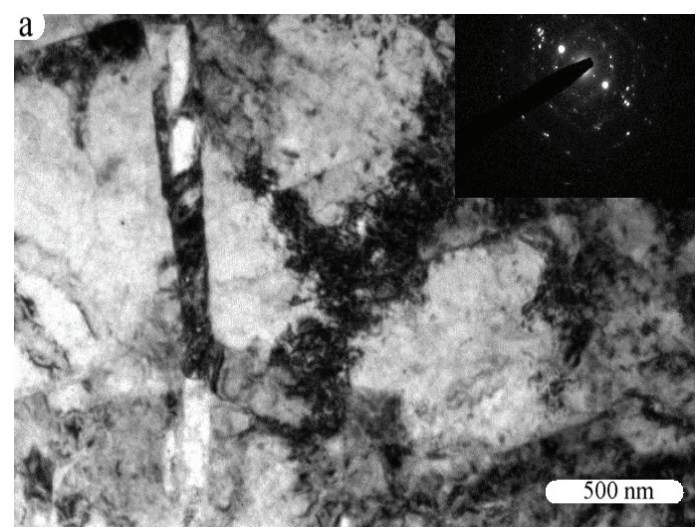




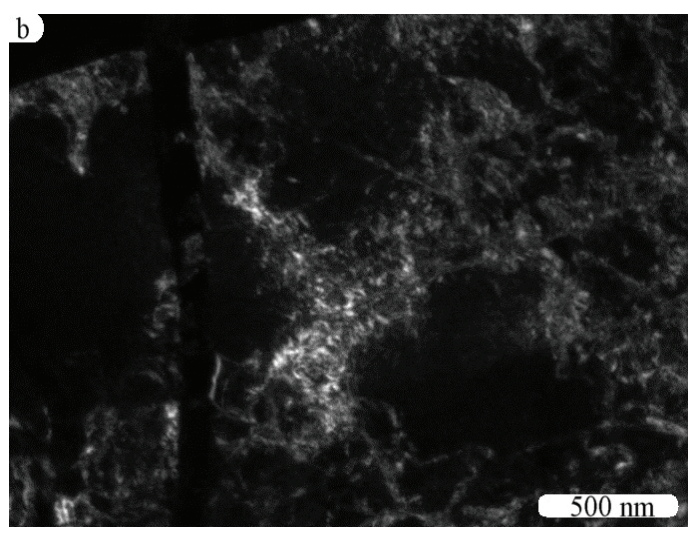

Fig. 4. Microstructure of the $\mathrm{Ti}_{49.1} \mathrm{Ni}_{50.9}$ alloy subjected to ECAP-C $\left(n=4, T=400^{\circ} \mathrm{C}\right)$ : bright-field image (a); dark-field image (b).

As the strain, further increases to 6 passes of ECAP$\mathrm{C}$, the size of fragments inside the bands decreases to $150 \mathrm{~nm}$. In some regions, twins are observed, induced by deformation or martensitic transformation (Fig. 5).
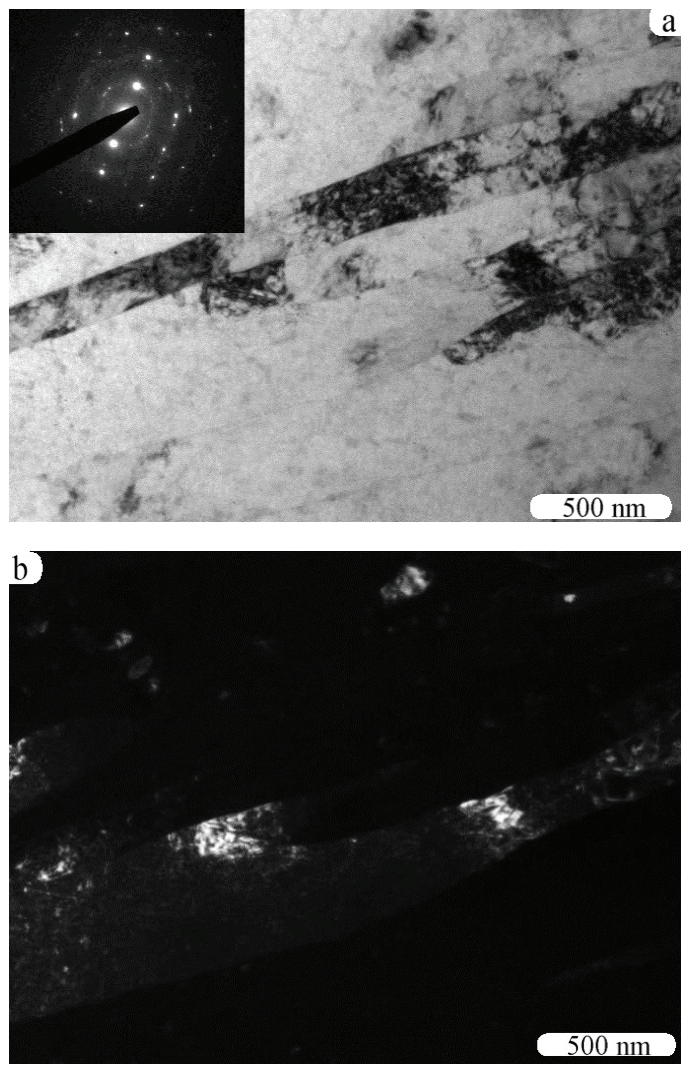

Fig. 5. Microstructure of the $\mathrm{Ti}_{49}{ }_{1} \mathrm{Ni}_{50.9}$ alloy subjected to ECAP-C $\left(n=6, T=450^{\circ} \mathrm{C}\right)$ : bright-field image (a); dark-field image (b).

Subsequent annealing at $500^{\circ} \mathrm{C}$ after ECAP-Conform processing with the number of passes $n=6$ leads to the formation of a structure with a grain size of $\sim 200 \mathrm{~nm}$ (Fig. 6).

Note should be made that in the condition «ECAP-C $\mathrm{n}=6$ » after annealing at $500^{\circ} \mathrm{C}$, the grain/subgrain boundaries are revealed much more distinctly (Fig. 6) than in the conditions prior to annealing (Fig. 4-5). This can be attributed to the redistribution of dislocations, accumulated during ECAP-C processing, to the boundaries of grains and subgrains, and the transformation of loose and blurred boundaries into thinner and clearer boundaries.

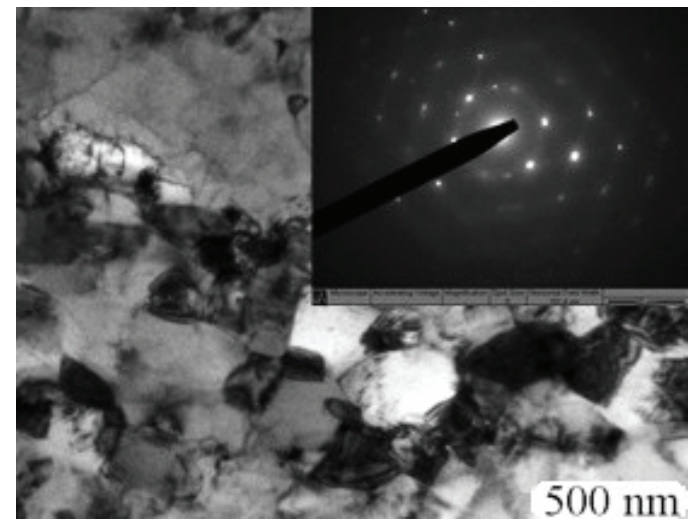

Fig. 6. Microstructure of the $\mathrm{Ti}_{49.1} \mathrm{Ni}_{50.9}$ alloy after ECAP-C $\left(\mathrm{n}=6, \mathrm{~T}=450^{\circ} \mathrm{C}\right)+$ annealing $\mathrm{T}=500^{\circ} \mathrm{C}$.

Table 1. The results of the estimation of bands and fragments.

\begin{tabular}{|c|c|c|c|}
\hline Condition & $\begin{array}{c}\text { The width of } \\
\text { the } \\
\text { fragments }\end{array}$ & $\begin{array}{c}\text { The length } \\
\text { of the } \\
\text { fragments }\end{array}$ & $\begin{array}{c}\text { The width } \\
\text { of the } \\
\text { bands }\end{array}$ \\
\hline $\begin{array}{c}\text { ECAP-C } \\
\mathrm{n}=2\end{array}$ & $450 \div 580$ & $450 \div 650$ & $340 \div 500$ \\
\hline $\begin{array}{c}\text { ECAP-C } \\
\mathrm{n}=4\end{array}$ & $300 \div 500$ & $380 \div 590$ & $140 \div 200$ \\
\hline $\begin{array}{c}\text { ECAP-C } \\
\mathrm{n}=6\end{array}$ & $210 \div 320$ & $290 \div 450$ & $210 \div 380$ \\
\hline $\begin{array}{c}\text { ECAP-C } \\
\mathrm{n}=6+ \\
\text { annealing } \\
500^{\circ} \mathrm{C}\end{array}$ & $130 \div 230$ & $180 \div 340$ & $250 \div 400$ \\
\hline
\end{tabular}

\subsection{Mechanical properties of $\mathrm{Ti}_{49.1} \mathrm{Ni}_{50.9}$ alloy}

The results of mechanical tests show that ECAP-C processing leads to an intensive growth of strength $\left(\sigma_{\mathrm{B}}\right)$ and yield strength $\left(\sigma_{\mathrm{y}}\right)$, as compared to the initial asquenched condition (table 2).

Table 2. Mechanical properties of the TiNi alloy.

\begin{tabular}{|c|c|c|c|c|}
\hline Condition & $\begin{array}{c}\sigma_{\mathrm{B}}, \\
\mathrm{MPa}\end{array}$ & $\begin{array}{c}\sigma_{0.2}, \\
\mathrm{MPa}\end{array}$ & $\begin{array}{c}\sigma_{\mathrm{m}}, \\
\mathrm{MPa}\end{array}$ & $\delta, \%$ \\
\hline Initial & 963 & 565 & 300 & 21 \\
\hline ECAP-C $\mathrm{n}=2$ & 1060 & 835 & 210 & 27 \\
\hline ECAP-C $\mathrm{n}=4$ & 1150 & 930 & 360 & 24 \\
\hline ECAP-C $\mathrm{n}=6$ & 1320 & 1205 & 343 & 24 \\
\hline $\begin{array}{c}\text { ECAP-C } \mathrm{n}=6 \\
\mathrm{~T}=450^{\circ} \mathrm{C}+\text { annealing } \\
500^{\circ} \mathrm{C}\end{array}$ & 1120 & 970 & 290 & 27 \\
\hline
\end{tabular}

Already after 2 passes the strength characteristics increase to $1060 \mathrm{MPa}$. After ECAP-C processing with the number of passes $n=6$, the ultimate tensile strength grows to $1320 \mathrm{MPa}$, the elongation being $24 \%$. The dislocation yield strength grown from an initial value of 
$565 \mathrm{MPa}$ to $835 \mathrm{MPa}$ at $\mathrm{n}=2$ and to $1205 \mathrm{MPa}$ at $\mathrm{n}=6$. It should be noted that the relative increment, resulting from ECAP-C processing, in yield strength is visibly higher than the one in ultimate tensile strength $(110 \%$ and $40 \%$, respectively).

The significant increase in dislocation yield strength as a result of ECAP-C processing makes it possible to expect enhanced characteristics of the shape memory effect - reactive stresses and reversible strain, as was earlier observed in TiNi alloys subjected to conventional ECAP [6].

The results of microhardness testing after ECAP-C processing with the number of passes $n=2-6$ show that as strain increases and, consequently, as the structure becomes more refined, microhardness growth occurs (table 3), which is in agreement with the data from the mechanical tests.

Table 3. Results of microhardness testing.

\begin{tabular}{|c|c|}
\hline Condition & $\begin{array}{c}\text { Microhardness (HV), } \\
\mathrm{MPa}\end{array}$ \\
\hline $\mathrm{CG}$ & $2585 \pm 110$ \\
\hline ECAP-C $\mathrm{n}=2$ & $3100 \pm 85$ \\
\hline ECAP-C $\mathrm{n}=4$ & $3450 \pm 170$ \\
\hline ECAP-C $\mathrm{n}=6$ & $3740 \pm 150$ \\
\hline $\begin{array}{c}\text { ECAP-C } \mathrm{n}=6+ \\
\text { annealing } 500^{\circ} \mathrm{C}\end{array}$ & $3515 \pm 110$ \\
\hline
\end{tabular}

\section{Conclusions}

1. Using ECAP-Conform processing with the number of passes $\mathrm{n}=2,4,6$, integral rods of the $\mathrm{Ti}_{49.1} \mathrm{Ni}_{50.9}$ alloy have been produced. TEM studies demonstrate that in the alloy there forms a banded deformation structure with a structural element size of up to $150 \mathrm{~nm}$, after ECAP-C processing with $\mathrm{n}=6$;

2. Annealing at a temperature $500^{\circ} \mathrm{C}$ of the alloy in the condition after ECAP-C processing with $n=6$ has led to the redistribution of the dislocations, accumulated during ECAP-C processing, to the boundaries of grains and subgrains, and to the formation of a structure with a grain/subgrain size of $\sim 200 \mathrm{~nm}$;

3. The performed mechanical tests show that as a result of increasing number of ECAP-C cycles, the ultimate tensile strength grows from an initial value of $963 \mathrm{MPa}$ to $1320 \mathrm{MPa}$ for ECAP-C processing with $\mathrm{n}=6$, while the dislocation yield strength increases from an initial value of $565 \mathrm{MPa}$ to $1205 \mathrm{MPa}$. Meanwhile, ductility is retained at an acceptable level of $25 \%$.

This work was supported by grant No. 6.37.204.2016 from Saint Petersburg State University. This work was also supported by RFBR grant No. 16-38-00242.

\section{References}

1. V. Brailovski, S. Prokoshkin, P. Terriault, F. Trochu, Shape Memory Alloys: Fundamentals, Modeling and Applications (Ecole de Technologie
Superieure (ETS), Universite du Quebec, Montreal, Canada, 2003)

2. K. Otsuka, X. Ren, Prog. Mater. Sci. 50, (2005)

3. R.Z. Valiev, Y. Estrin, Z. Horita, T.G. Langdon, M.J. Zehetbauer, Y.T. Zhu, JOM 58 (2006)

4. R.Z.Valiev, A.P. Zhilyaev, T.G. Langdon, Bulk Nanostructured Materials: Fundamentals and Applications (John Wiley \& Sons, Inc., Hoboken, New Jersey, 2014)

5. A.V. Sergueeva, C. Song, R.Z. Valiev, A.K. Mukherjee, Mater. Sci. Eng. A 339 (2003)

6. I.Yu. Khmelevskaya, S.D. Prokoshkin, I.B. Trubitsyna, M.N. Belousov, S.V. Dobatkin, E.V. Tatyanin, A.V. Korotitskiy, V. Brailovski, V.V. Stolyarov, E.A. Prokofiev, Mater. Sci. Eng. A 481482 (2008)

7. V.G. Pushin, R.Z. Valiev, Y.T. Zhu, D.V. Gunderov, T.E. Kuntsevich, N.I. Kourov, A.N. Uksusnicov, L.I. Yurchenko, Mater. Trans. 47 (2006)

8. V.G. Pushin, V.V. Stolyarov, R.Z. Valiev, T.C. Lowe, Y.T. Zhu, Mater. Sci. Eng. A 410-411 (2005)

10. R.Z. Valiev, D.V. Gunderov, A.V. Lukyanov, V.G. Pushin. J. Mater. Sci. 47 (2012)

11. D. Gunderov, A. Lukyanov, E. Prokofiev, A. Churakova, V. Pushin, S. Prokoshkin, V. Stolyarov, R. Valiev. Mater. Sci. Forum. 738-739 (2013)

12. E.A. Prokofiev, J.A. Burow, E.J. Payton, R. Zarnetta, J. Frenzel, D.V. Gunderov, R.Z. Valiev, G. Eggeler, Adv. Mater. Eng. 12 (2010)

13. G.I. Raab, E.P. Soshnikova, R.Z. Valiev, Mater. Sci. Eng. A 387 - 389 (2004)

14. G.J. Raab, R.Z. Valiev, T.C. Lowe and Y.T. Zhu, Mater. Sci. and Eng. A 382 (2004)

15. G.I. Raab, F.F. Safin, T.C. Lowe, Y.T. Zhu, and R.Z. Valiev, Ultrafine Grained Materials IV. TMS Ultrafine Grained Materials IV (2006)

16. G.I. Raab, R.Z. Valiev, D.V. Gunderov, T. Lowe, A. Misra, Yu. Zhu Long-length, Mater. Sci. Forum, 584-586 (2008)

17. G.I. Raab, A.V. Polyakov, D.V. Gunderov, R.Z. Valiev, Russian Metallurgy (Metally), 5 (2009) 